\title{
Citizen science participation in research in the environmental sciences: key factors related to projects' success and longevity
}

\author{
DAVI G.F. CUNHA ${ }^{1}$, JONATAS F. MARQUES ${ }^{1}$, JULIANA C. DE RESENDE ${ }^{1}$, PATRÍCIA \\ B. DE FALCO ${ }^{2}$, CHRISLAINE M. DE SOUZA ${ }^{3}$ and STEVEN A. LOISELLE \\ ${ }^{1}$ Departamento de Hidráulica e Saneamento, Escola de Engenharia de São Carlos, Universidade de São \\ Paulo, Avenida Trabalhador São-Carlense, 400, Centro, 13566-590 São Carlos, SP, Brazil \\ ${ }^{2}$ Universidade Federal de São Carlos, Rodovia Washington Luís, s/n, Jardim Guanabara, 13565-905 São Carlos, SP, Brazil \\ ${ }^{3}$ Earthwatch Institute, Oxford, 256 Banbury Rd, Oxford OX2 7DE, United Kingdom
}

Manuscript received on August 24, 2016; accepted for publication on March 1, 2017

\begin{abstract}
The potential impacts of citizen science initiatives are increasing across the globe, albeit in an imbalanced manner. In general, there is a strong element of trial and error in most projects, and the comparison of best practices and project structure between different initiatives remains difficult. In Brazil, the participation of volunteers in environmental research is limited. Identifying the factors related to citizen science projects' success and longevity within a global perspective can contribute for consolidating such practices in the country. In this study, we explore past and present projects, including a case study in Brazil, to identify the spatial and temporal trends of citizen science programs as well as their best practices and challenges. We performed a bibliographic search using Google Scholar and considered results from 2005-2014. Although these results are subjective due to the Google Scholar's algorithm and ranking criteria, we highlighted factors to compare projects across geographical and disciplinary areas and identified key matches between project proponents and participants, project goals and local priorities, participant profiles and engagement, scientific methods and funding. This approach is a useful starting point for future citizen science projects, allowing for a systematic analysis of potential inconsistencies and shortcomings in this emerging field.
\end{abstract}

Key words: Citizen science, community-based monitoring, environmental management, public participation, volunteer data collection.

\section{INTRODUCTION}

Participation of non-experts in environmental management and monitoring is emerging as one of the most important issues since the environmental movement of the 1960-70s (Kenney 1999, 2001). Citizen science has the potential to generate the

Correspondence to: Davi Gasparini Fernandes Cunha

E-mail: davig@sc.usp.br social capital necessary for collective action to resolve large scale environmental problems (Overdevest et al. 2004) and favor behavioral changes for both individuals and groups (Toomey and Domroese 2013). Participation in citizen science programs can enhance decision making processes by governments, companies and institutions (Sinclair and Diduck 2001) and ensures a better understanding of key issues by different 
stakeholders (Conrad 2006, Cooper et al. 2007, Ely 2008, Haywood and Besley 2014). Public engagement, scientific learning, socialization and awareness raising are often important results from citizen science programs (Conrad and Hilchey 2011, Lowry and Fienen 2013).

Recent citizen science projects on biodiversity, ecosystems functioning, species distribution, water, soil and air quality have shown that productive partnerships between scientists and the public can be formed (Toomey and Domroese 2013, Thornhill et al. 2016). The increase in spatial and temporal resolution of environmental information made possible by citizen science makes these programs an attractive choice for monitoring and research activities where high resolution data are necessary (Devictor et al. 2010, Newman et al. 2011, Krasny et al. 2014). Citizen science initiatives can span different environmental scales, from biome and biogeographical studies to specific evaluations of local issues (e.g., biological communities and fauna-environment interactions) (Wei et al. 2016, Loiselle et al. 2016), being the latter approach still more common.

The term "citizen science" is widely used to denote voluntary participation of citizens in scientific data gathering and/or analysis (Dickinson et al. 2012, Roy et al. 2012, Donnelly et al. 2014). When a community takes the responsibility to collect data on their local environment, citizen science can be denoted as community-based monitoring (Conrad and Hilchey 2011). Despite such conceptual differences, volunteer participation in environmental monitoring, as citizen science or community-based monitoring, is increasing in practice (Au et al. 2000, Conrad 2006, Couvet et al. 2008). Interestingly, best practices for project implementation and volunteer engagement still remain unclear (Stewart and Sinclair 2007, O’Faircheallaigh 2010).

In Brazil, the citizen science approach has been usually limited to local projects. Bird watching for assessing biodiversity associated with ecoturism activities was reported in a project in Ubatuba (São Paulo State) (Dias and Figueira 2010). A biotic index for volunteer monitoring was proposed for water quality assessment of Brazilian streams at Espírito Santo State (Buss 2008). A recent Brazilian case of citizen monitoring activities occurred after the collapse of a mining dam in Mariana (Minas Gerais State). Immediately following the incident (in 2015), volunteers organized themselves to produce information regarding the environmental impacts of the release of the iron ore tailings. One of the most active groups of volunteers is GIAIA (Grupo Independente para Avaliação do Impacto Ambiental, see GIAIA 2016). While all these projects are fundamental to produce important information for decision making and environmental assessment, the integration among such initiatives and the development of common methodologies and performance indicators are still lacking. Since Brazil is a large country with different biomes (e.g., Atlantic Rainforest, Amazon, Pantanal, Cerrado, Caatinga and Pampa), the integration of volunteer monitoring of local natural resources, water, soil and biodiversity could be a cost effective mean to gather high resolution data and support environmental management.

The present study examined spatial and temporal trends of citizen science programs to determine commonalities, best practices, and major opportunities and challenges. We identified a preliminary list of key factors to compare, in a systematic manner, the basic structure and function of these disparate projects. We tested this approach in a large scale citizen science project on freshwater ecosystems in Brazil, putting this project into the global context. Although there are other review papers available in the literature (Couvet et al. 2008, Elwood 2010, Magurran et al. 2010, Wiggins and Crowston 2011, Catlin-Groves 2012, Ferster and Coops 2013), our research shows that there is a higher diversity on citizen science initiatives 
than usually reported. This review represents an attempt to systematize and analyze these projects to identify potential inconsistencies and shortcomings in this emerging field and how these projects are reported.

\section{MATERIALS AND METHODS}

A bibliographic search using Google Scholar was used to identify the main characteristics of ongoing or past citizen science projects in the last ten years (2005-2014). Two major search terms were used ("citizen science" and "monitoring"), combined with the logical operator AND to determine the number of publications available.

The search gave 7,770 results on May, 2015. The first 498 results were sorted by relevance according to the criteria: availability of full text, where it was published, how often and how recently cited (About Google Scholar 2015). Based on the journal type, the manuscripts were classified in peer-reviewed or not peer-reviewed, publication type and year. Using the sub dataset of articles published in peerreviewed journals $(n=303)$, keyword frequency was analyzed to identify the importance of the themes and topics discussed (Figure 1).

Although the criteria for ranking publications and the searching algorithms of Google Scholar are not completely clear, studies have shown that the article's citation count has a significant impact on the retrieved ranking of publications (Beel and Gipp 2009a, b). One important consequence of this is that publications with different views to the mainstream are more likely to be unrepresented (Beel and Gipp 2009a). However, one of the advantages of using Google Scholar is that it gives a better understanding of the international and interdisciplinary views of the scholarly community (Yang and Meho 2007), with a diverse content from different angles.

Another sub dataset $(n=126)$ of publications was filtered according to the following criteria: [1] papers describing the activities of the monitoring scheme (such as volunteers training and protocols of data quality assurance etc.); [2] papers reporting the experiences from citizen science projects; [3] papers presenting results and conclusions

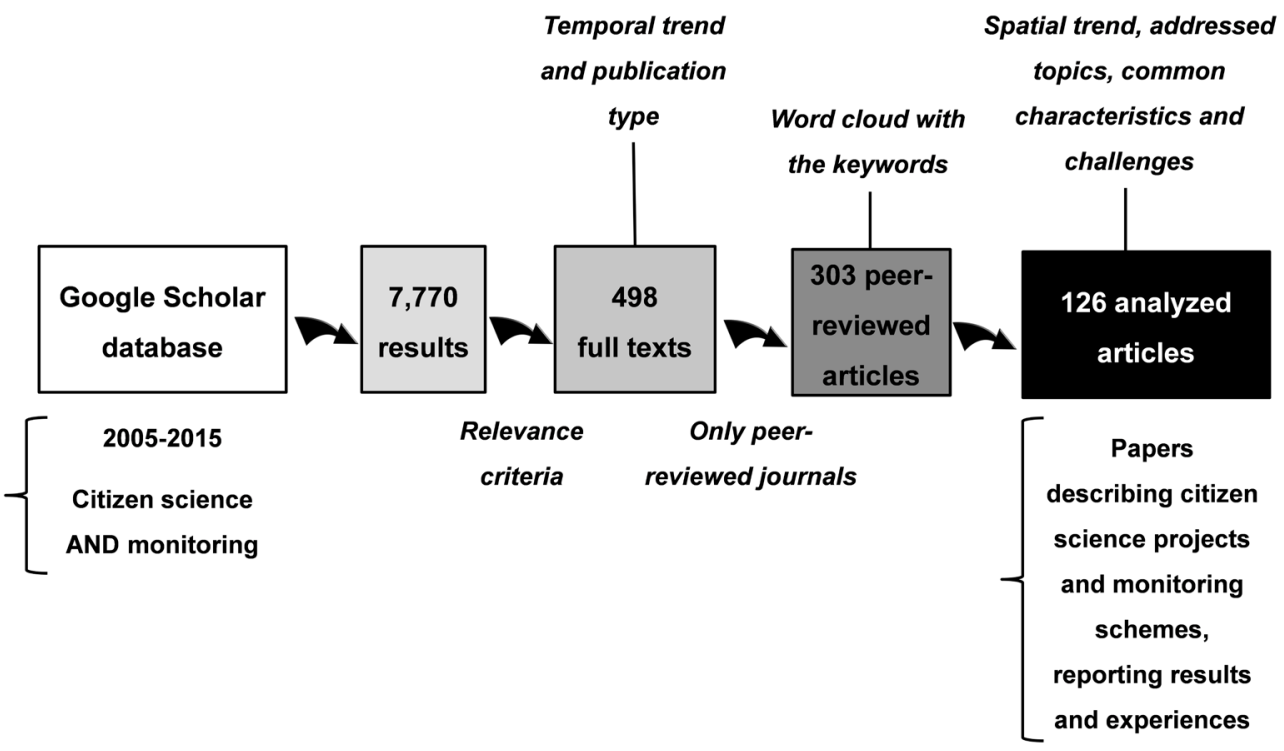

Figure 1 - Literature review using Google Scholar and filtering criteria. 
of scientific research based on citizen scientist acquired data.

The citizen science projects found were classified in terms of monitoring type and biological topic. The projects with no strict components on biological communities (such as earthquake monitoring and astronomy) were also included. For each analyzed publication, information related to the impact of the project (e.g., human resources required, project implementation and continuation, financial sustainability and communication) was used to identify common challenges and barriers, as well as the main opportunities and projects' outcomes. These data were used in a comparative analysis according to the relative frequency for each category. For example, regarding the "funding source" of a given project, the options were public/ government, non-governmental organization, private, university or no information provided.

Finally, information from a multiple city Brazilian citizen science project "Adopt a River" was used to examine key issues related to project sustainability. This project is part of the FreshWater Watch (FWW), a global mass citizen science program supporting scientists in more than 30 cities (on five continents) using a common methodology and framework.

\section{RESULTS AND DISCUSSION}

\section{CHARACTERIZATION OF THE PUBLICATIONS FROM THE DATABASE}

Our literature review was performed through Google Scholar with the search terms "citizen science" and "monitoring". As any other search engine, the use of Google Scholar filters publications according to specific (and not always explicit) criteria, with associated consequences for data mining and interpretation. Pros and cons of using Google Scholar are comprehensively described by Jacsó (2008), with the main strengths related to the vast content of the source base and the main weaknesses associated with the search software. Our search results were therefore subject to the ranking algorithm used by Google Scholar, where highlycited documents are more frequently retrieved (Martin-Martin et al. 2017), possibly attributing more weight to "classic" or old publications (with more time available for being cited).

The language of the search terms is also an important caveat. English was used, leaving out publications in other languages, such as Portuguese or Spanish. For example, Brazilian papers published in Portuguese and in local journals with limited circulation were not considered, allowing for possible inconsistencies in the assessment of the project geographic location. However, English is the most commonly used language for scientific publications and as the most popular search engine in colleges and universities (Neuhaus et al. 2008), it is expected to index the greatest number of core/fundamental articles on different fields (e.g., Walters 2007). Therefore, we consider the analyzed publications in this study are representative of citizen science papers produced by the scientific community between 2005 and 2014.

The worldwide increase in citizen science initiatives was reflected in the number of manuscripts and other academic texts published in the last 10 years (Figure 2). There was an increase from 2005 to 2012, with a maximum conditioned by two special editions of Frontiers in Ecology and the Environment (14 manuscripts) and Nature (11 manuscripts). The publications were dominated by journal manuscripts (67\%), followed by conference proceedings (15\%) and book chapters $(7 \%)$ (Figure $3)$. Most of the articles were published in peerreviewed journals $(61 \%)$.

Following "citizen science" and "monitoring", the keywords "conservation", "biodiversity" and "climate change" were the most common of the 1,130 keywords in the 303 peer-reviewed papers (Table I, Figure 4). This highlights the importance of citizen science for long term 


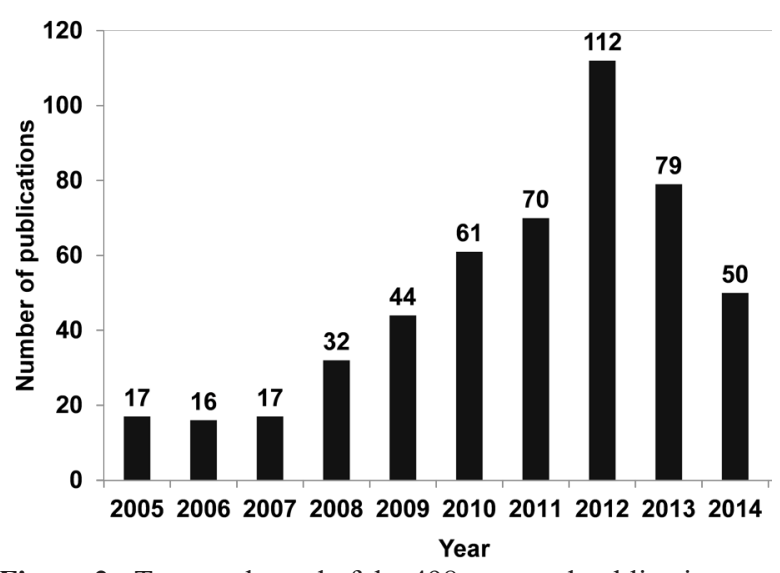

Figure 2 - Temporal trend of the 498 screened publications on citizen science from 2005 to 2014.

biological monitoring. Other common keywords addressed tools for data analyses (e.g., indicators, GIS and census), environmental compartments or processes (pollution, diversity, wildlife, climate and bird) and the indirect results (decision-making, democratizing, public, change and participatory).

Publications $(n=126)$ showed a clear geographic imbalance (Figure 5), with the North America (58\%), and more specifically United States (46\%) having the largest number of published studies, followed by Europe, with 24\%. Few initiatives were reported in Africa, Asia and Oceania, and even less in Central and South America. This discrepancy is significant when compared to the national scientific output of these same regions: United States (24\%) Europe (35\%), China (10\%) and South America (3\%) (www.scimagojr.com). One explanation for this discrepancy may be the lack of national (private or public) funding schemes, limited internet access and limited public participation in environmental decision making in several of these regions (Şekercioğlu 2012, Burgos et al. 2013, Kebo and Bunch 2013, Sheppard et al. 2014). Few $(n=4)$ studies had a transnational or global geographic focus.

While the biome where the projects were conducted is not often described, we expect temperate biomes are more frequently studied

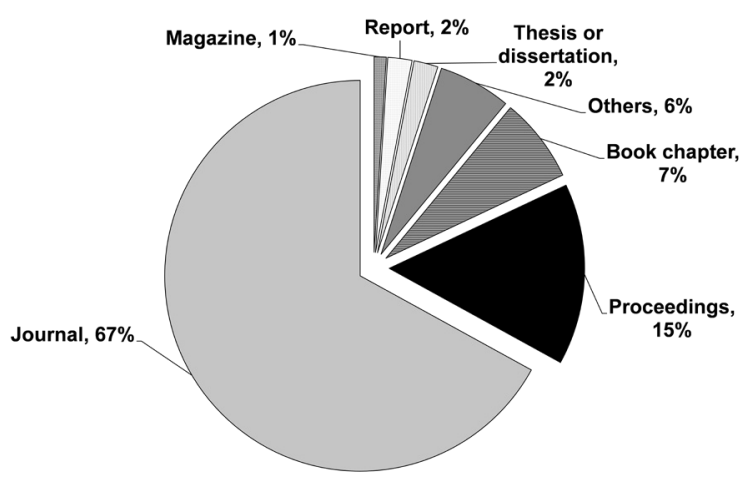

Figure 3 - Distribution of publications on citizen science $(n=498)$ from 2005 to 2014 according to the type of publication. "Other types": equal or less than $1 \%$ of the total.

as consequence of the geographic distribution of citizen science projects. Such biomes include broadleaf and mixed forests, coniferous forests, grasslands, savannas, and shrublands. Although not biome specific, many projects focused on questions about biodiversity, species population and distribution (e.g., Beasley et al. 2012 for cicadas and Abolafya et al. 2013 for birds).

Most citizen science studies focused on biological monitoring ( $\mathrm{n}=98,77 \%)$ (Table II), followed by coastal marine $(n=12,9 \%)$ and freshwater $(n=7,6 \%)$ monitoring programs. Noise, earthquake, air and other monitoring studies accounted for another 7\%. Both biology and ecology have a long history of volunteer data collection (Bonney et al. 2009a, b) related to species and population tracking, invasive species evaluation and habitat studies. Studies related to bird populations were the most common and have the longest history of activity (Lepczyk 2005).

Published citizen science projects on water quality were less frequent and commonly focused on freshwater ecosystems, although studies of coastal marine ecosystems were reported (Arvanitidis et al. 2011). Freshwater studies are facilitated by their common presence in most population centers. Most of these studies acquire information about habitat or water quality through the use of relatively 
TABLE I

Ten keywords (with or without spaces) with the highest absolute and relative frequency (\%) from the 303 analyzed peerreviewed articles.

\begin{tabular}{cccccc}
\hline Keywords & $\begin{array}{c}\text { Absolute } \\
\text { frequency }\end{array}$ & $\begin{array}{c}\text { Relative } \\
\text { frequency (\%) }\end{array}$ & $\begin{array}{c}\text { Keywords } \\
\text { without spaces }\end{array}$ & $\begin{array}{c}\text { Absolute } \\
\text { frequency }\end{array}$ & $\begin{array}{c}\text { Relative frequency } \\
\text { (\%) }\end{array}$ \\
\hline Citizen science & 97 & 8.6 & Science & 117 & 5.7 \\
Monitoring & 21 & 1.9 & Citizen & 107 & 5.2 \\
Conservation & 9 & 0.8 & Monitoring & 82 & 4.0 \\
Biodiversity & 8 & 0.7 & Data & 25 & 1.2 \\
Climate change & 8 & 0.7 & Biodiversity & 25 & 1.2 \\
Volunteers & 7 & 0.6 & Conservation & 24 & 1.2 \\
Invasive species & 7 & 0.6 & Species & 21 & 1.0 \\
Distribution & 7 & 0.6 & Environmental & 20 & 1.0 \\
Volunteer & 6 & 0.5 & Management & 17 & 0.8 \\
Data quality & 6 & 0.5 & Change & 17 & 0.8 \\
\hline
\end{tabular}

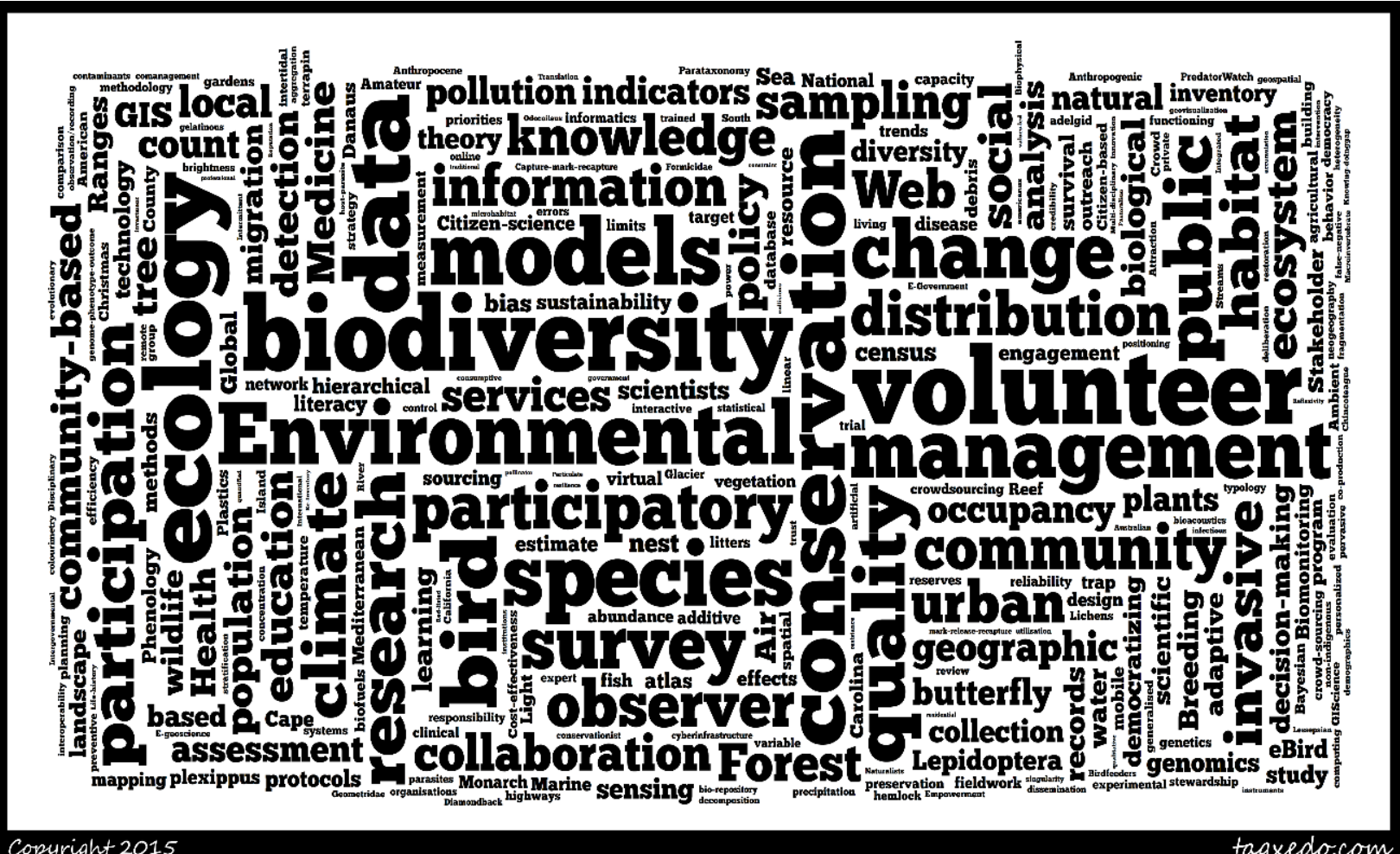

Figure 4 - Word cloud for the first 400 keywords of the peer-reviewed papers analyzed in this study, www.tagxedo.com. The size of each word is proportional to the relative frequency it is mentioned in the texts. 
simple observations (e.g., algal blooms, stream bank vegetation). More complex and quantitative studies using citizen science grade measurements of turbidity, temperature, concentrations of dissolved oxygen, nutrients, fecal coliforms or invertebrates (requiring additional training and support) were limited (Kim et al. 2011). Data quality represents a major challenge in these projects and secondary information sources (photographic or confirmatory observations) are often used (Lowry and Fienen 2013).

\section{SEVEN KEY FACTORS}

Based on the publication dataset $(n=126)$, seven factors were identified based on project participants (scientists and volunteers) and structure. These factors were used to characterize and compare projects across geographical and disciplinary areas (Figure 6):

a. Project proponents. What is the main institution or group of people responsible for the conception and initiation of the citizen science project? Government, Non-Governmental Organization, Private Business or University.

b. Funding sources. What is the main provider of financial resources for developing project activities? Government, Non-Governmental Organization, Private Business or University.

c. Volunteer profiles. Where do the volunteers come from? Public from government institutions (e.g., civil service), General public (e.g., scuba divers), NonGovernmental Organization, Private sector or University.

d. Volunteer commitment. How much time does each volunteer donate for the activity? One time (sporadic/random activity), Shortterm (less than one year) or Long-term (more than one year).

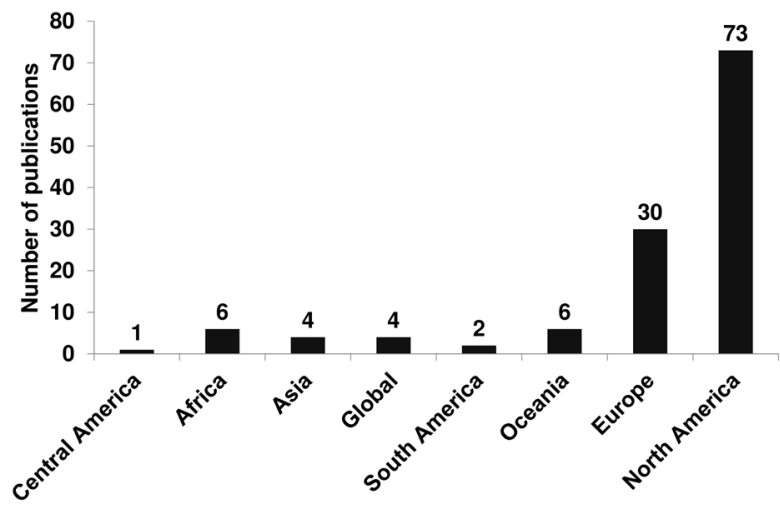

Figure 5 - Geographic distribution of the citizen science projects analyzed $(n=126)$.

TABLE II

Absolute distribution of the topics addressed by the selected citizen science papers in relation to the monitoring scope.

\begin{tabular}{lc}
\hline Topic & Number of projects \\
\hline Biological monitoring & $98^{\dagger}$ \\
Coastal monitoring & 12 \\
Water monitoring & 7 \\
Urban ecosystems & 3 \\
Earthquakes monitoring & 2 \\
Astronomy studies & 1 \\
Genomic studies & 1 \\
Health research & 1 \\
Air monitoring & 126 \\
\hline Thetal & \\
\hline
\end{tabular}

The following distribution was observed concerning the biological specific topics: plants (20), birds (19), insects (18), mammals (14), fish (6), amphibians (3), reptiles (2), macroinvertebrate (2) and other cases (14). 


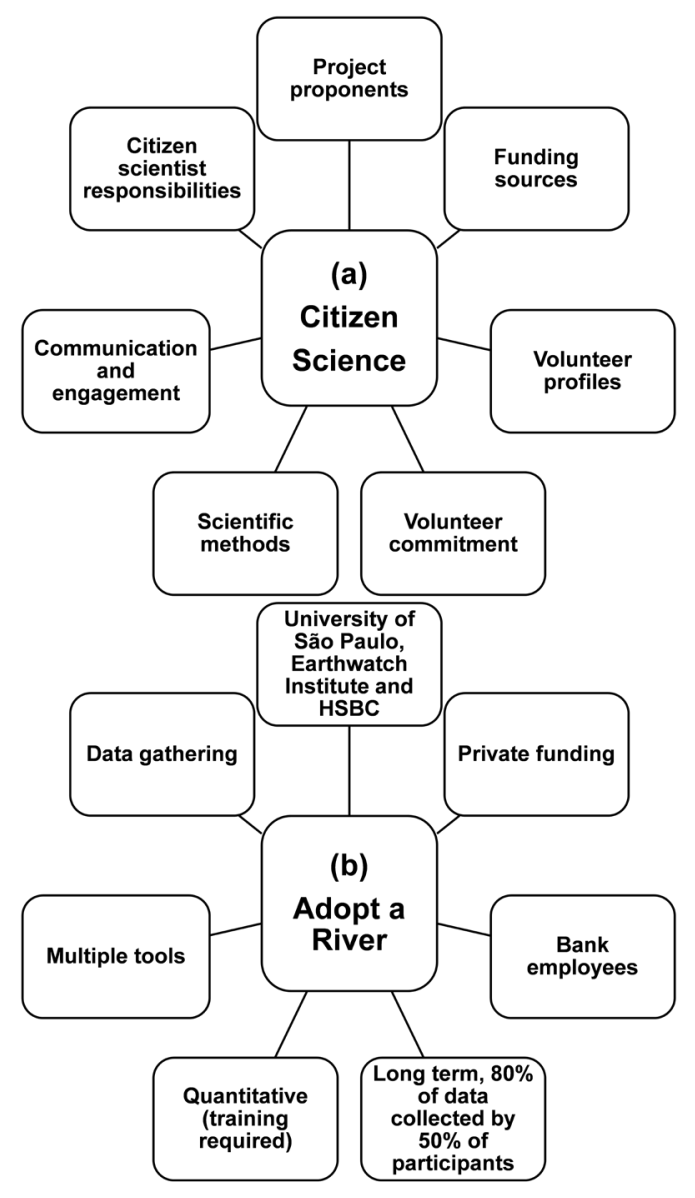

Figure 6 - Seven elements related to project structure and participants in the analyzed citizen science projects (a) and in the "Adopt a River" project (b).

e. Scientific methods. What are the main characteristics of the citizen scientist activity and relative requirements for training? Observational data gathering (training or no training required) or Quantitative data gathering (training or no training required).

f. Communication and engagement. What are the main strategies for communication between project coordinators and volunteers to insure engagement and activity rates? Meetings (one or regular), Continuous learning or Online interaction.

g. Citizen scientist responsibilities. What are the volunteers responsible for? Data gathering, Data analyses and interpretation or Quality control.
In most cases, reported projects were initiated by universities (35\%, Figure 7a), NGOs (11\%) or similar social agents. The most common "multiple" proponents were "university + NGOs", "government + NGOs" and "university + government + NGOs" partnerships, making up for $65 \%$ of the cases within this category. Scientists were the most common initiator, with the typical objective to increase data gathering or analysis capability or to increase engagement and awareness. NGOs, community trusts and concerned citizen groups were also initiators, usually focused on a local or sectorial area with value to the local community. The combination of the two (scientists and concerned public) provides two major elements which are often lacking individually: recruitment with long term engagement and scientific rigor. The private sector was not represented as a proponent, although there was no clear information on project proponents in $27 \%$ of the projects analyzed (Figure 7a).

Although the cost of citizen science monitoring activities is expected to be lower than conventional approaches, financial support is fundamental, not only for monitoring activities, but also for training, engagement, feedback and quality control (Danielsen et al. 2009, DeLuca et al. 2010). Multiple-source funding was the most common characteristic of the studied projects (32\%, Figure 7b). These included shared funding among universities, NGOs, private and public agencies. Co-funding was seen as a key element in the project sustainability (Conrad and Hilchey 2011, Wright and Stevens 2012) and can be an interesting alternative for developing countries, including those from Latin America. Governmental agencies ( $21 \%$ of the cases) often had the role of facilitator, and are a natural beneficiary of citizen science on improved information flows and public awareness. In recent years (2014 to the present), a number of national and transnational public programs have been initiated. 
(a) Project proponents

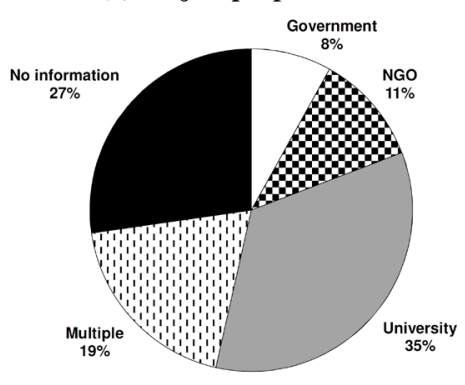

(d) Volunteer commitment

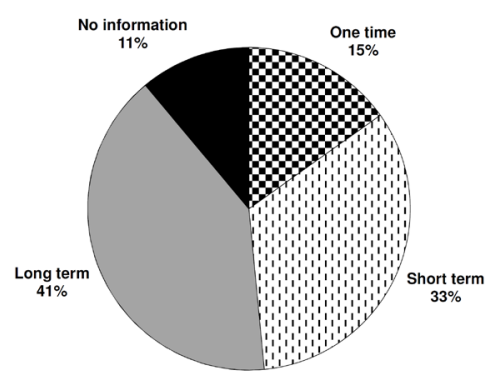

(b) Funding sources

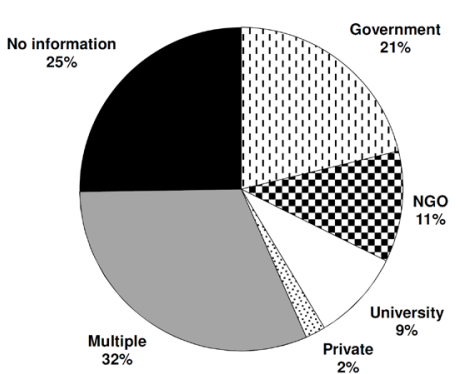

(e) Scientific methods

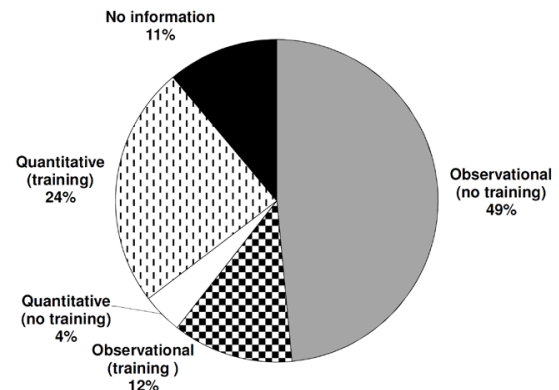

(g) Citizen scientist responsibility

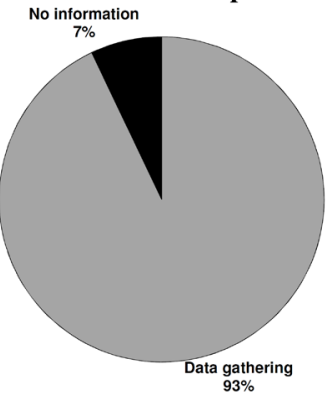

(c) Volunteer profiles

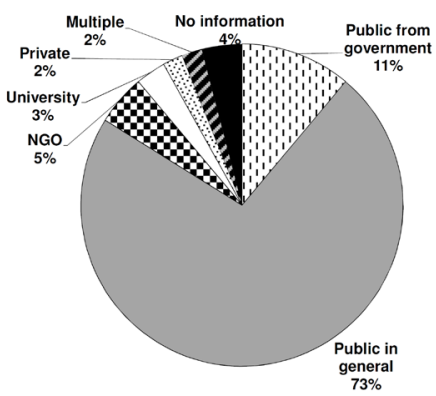

(f) Communication and engagement

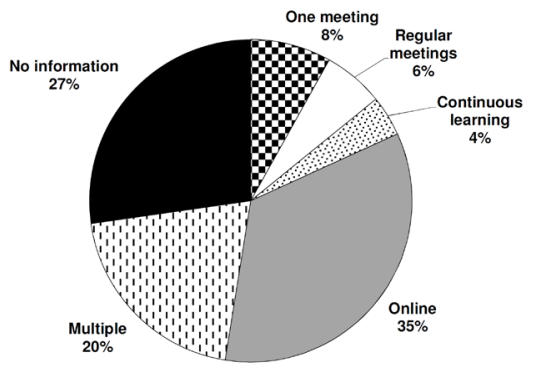

Figure 7 - Characterization of the 126 analyzed citizen science projects regarding: project proponents (a), funding sources (b), volunteers profiles $(\mathbf{c})$, volunteer commitment $(\mathbf{d})$, scientific methods (e), communication and engagement (f) and citizen scientist responsibility (g). "No information" means the information was never provided or, if provided, was unclear.

The European Commission's “Citizen Observatories" includes the objective to improve in-situ data collection through partnerships between the private and public actors. In North America, an array of US Federal agencies has joined the Federal Community of Practice on Crowdsourcing and Citizen Science to improve government's use of citizen science to enhance scientific and societal outcomes (Conrad and Daoust 2008). Private initiatives (Google Impact Award, HSBC Water Programme) are increasingly providing necessary funding for these initiatives, although exclusive private funding has not been very common $(2 \%$, Figure $7 \mathrm{~b}$ ). The combined trends of increased public attention to local environmental conditions (Daniels et al. 2012) and financial pressures on agency monitoring has created an opportunity for complementary data gathering methods of environmental conditions, including citizen science (DeLuca et al. 2010, Wright and Stevens 2012, Thornhill et al. 2016). One clear advantage of citizen monitoring is that volunteers can cover significant areas of the territory as they can be numerous and live in different watersheds, regions and biomes.

Citizen scientists were characterized by different ages and levels of education (Evans et al. 2005, Silvertown 2009). Most projects were 
focused on the general public with no restrictions (73\%, Figure 7c), although some were for specific groups such as scuba divers, biologists or high school students. Project methodology reflected the motivations and capabilities of the target volunteer profile to avoid bias in the dataset and loss of motivation due to frustration (Couvet et al. 2008, Brook et al. 2009). Hobbs and White (2012) identified barriers to participation that vary across different social and ethnic groups. People at lower socio-economic levels were less represented most likely due to a lack of opportunities, motivation and accessibility.

Long term commitment in citizen science projects provides benefits to data quality and quantity. Long term commitment (more than one year) $(41 \%)$ exceeded the cases of short term and one time participation (33\% and $15 \%$, respectively, Figure 7d). Pareto's rule characterizes output from citizen science or many crowdsourcing activities such as Wikipedia, where most data is obtained by a minority of very dedicated participants (Sauermann and Franzoni 2015). Likewise, commitment is related to person motivation, participation costs and time requirements. Personal motivation is subject to change, with an initial enthusiasm due to the opportunity to increase personal knowledge (Rotman et al. 2012). Continued engagement is associated to the presence of project mechanisms that support these personal goals together with social aspects of involvement (in communities, in scientific networks and in advocacy). Interactive features and data visualization tools (e.g., real-time maps, tables, and charts) are increasingly being used to sustain volunteers' commitment (Price and Dorcas 2011). Participation costs (time and financial) can be both a barrier to participation as well as an incentive for continued engagement. Also, barriers to democratic participation in decisionmaking influence motivation to participation, and lead to a feeling of "monitoring for the sake of monitoring" (Bäckstrand 2003, Sharpe and Conrad 2006).

The appropriateness of scientific methods and the training required for citizen science programs have a significant impact on data quality (Hunter et al. 2013, Tregidgo et al. 2013). Most published studies were based on observational data acquired by volunteers ( $49 \%$, Figure $7 \mathrm{e})$, with no training required. For example, the CrowdHydrology project (Lowry and Fienen 2013) aims at encouraging volunteers to submit hydrologic data by reading staff gauges. The second most common method was quantitative data acquisition with training required $(24 \%$, Figure $7 \mathrm{e})$. These included projects on population dynamics of specific organisms or biological groups with training costs ranging from little to multiple day sessions focused on safety procedures, monitoring protocols and equipment training (Brook et al. 2009, Ferreira et al. 2012). Inadequate training of the volunteers can compromise results and overall project efficiency (Milne et al. 2006, Conrad and Hilchey 2011). Mistrust from the scientific community regarding the participation of untrained people in scientific data gathering continues (McKinley et al. 2013); data reliability is one of the most contested aspects of citizen science (Catlin-Groves 2012). Statistical methods, new protocols and long-distance learning have been shown to improve the quality of information acquired by volunteers (Galloway et al. 2006, Devictor et al. 2010, Bird et al. 2014).

Previous studies indicate that communication among participants, scientists, and policy makers through different channels is the most important motivational factor for continued participation in citizen science projects (Rotman et al. 2012). However, information on communication and engagement was rarely reported in the published studies $(<25 \%)$ (Figure $7 \mathrm{f})$. Among those projects with available information, most depended upon online methods $(35 \%)$ to contact the volunteers and keep them active. Meeting with participants 
(14\%) and continuous learning activities (4\%) were other communication options, although multiple strategies were more frequent $(20 \%$, Figure 7f). In the absence of reported information on these aspects, a major challenge remains on how to evaluate the impact of citizen science on the scientific literacy of the participants (Cooper et al. 2007, Shwartz et al. 2012, Crall et al. 2013).

In the majority of the analyzed projects (93\%), volunteer activities were limited to data acquisition (e.g., samples, visual observations) (Figure 7g), with data analysis and interpretation performed by experts and scientists (e.g., School of Ants, Lucky et al. 2014). Other projects focused on data interpretation, usually by visual inspection (e.g., Galaxy Zoo). Combined approaches and volunteers contributing to interpretation of the data that they collect are more recent (Shirk et al. 2012, Toomey and Domroese 2013). This is expected to increase as online geographic information systems become more user friendly and expand to mobile devices and social media can facilitate citizen science programs (Daume et al. 2014). Mobile personal communication devices (e.g., camera, GPS, touch screen, microphones etc) can be used to obtain and share information on geographic platforms where volunteers can contribute to the interpretation of spatial trends.

\section{CASE STUDY IN BRAZIL - ADOPT A RIVER PROJECT}

The FreshWater Watch (FWW) is a citizen science project launched in 2012 in more than 30 cities (on five continents) to support local freshwater research in urban and peri-urban areas using a common methodology. A field based training day prepares volunteers to perform measurements in a safe and robust manner. Learning aspects include awareness raising of local and global freshwater issues, opportunities for community leadership and personal lifestyle changes. Participants form a global citizen scientist network through a multilanguage communication platform and are responsible for uploading data on environmental conditions and water quality of local aquatic systems in a common open-access database. The project falls into the "Water monitoring" category, which accounts for $6 \%$ of the assessed citizen science projects (Table II).

In the "Adopt a River" FWW project, citizen scientists are trained to monitor rivers and streams in three state capitals in Brazil (Curitiba, São Paulo and Rio de Janeiro) (Castilla et al. 2015), which were originally representative of at least two important Brazilian biomes: Cerrado and Mata Atlântica. The "Adopt a River" partners and promoters are the University of São Paulo, Earthwatch Institute and HSBC (Figure 6b), a collaboration of public, NGO and private sector partners. This would match the category "multiple proponents" considering the other analyzed projects worldwide (Figure 7a). The private bank was the key project funder, unusual as most projects were funded by other types of institutions (see Figure 2b). The training and long term engagement were performed by researchers from the University of São Paulo and Earthwatch Institute. HSBC volunteers participated in the training on a regular workday, while all monitoring activities are performed external to contracted work periods. Teams of trained volunteers adopted specific sites and made regular measurements under the guidance of researchers, using online and smart technologies. The use of citizen scientist teams promotes socialization and improves safety.

Participants come from different areas of the bank, with an average age of 37 years (ages from 21-59), and most have university degrees. The participants are encouraged to act as ambassadors of the program and encourage community, family members and friends to join them in monitoring activities. Participant questionnaires and surveys are used to evaluate training activities, the potential for behavioral change and the understanding of monitoring protocols. Over the first 24 months 
of the project, $94 \%$ of the participants identified a significant increase in their understanding of freshwater issues (local and global), 95\% reported a good to excellent understanding of the scientific protocols and 96\% reported an increased personal commitment to action.

After training, scientific engagement with the participants is maintained through multiple tools (Figure 6b). Feedback from researchers from the University of São Paulo and Earthwatch Institute includes weekly quality control messages, online seminars and a yearly report. Automated feedback is returned in near real time following data upload to the online database, and includes a comparative analysis of the uploaded dataset to local and global averages.

The participant teams make regular measurements using a standard global methodology with additional local parameters related to phytoplankton density and local meteorological conditions. Local parameters are related to ongoing research into the conditions leading to harmful algal blooms in these mostly unmonitored ecosystems (e.g., Cunha et al. 2011). All data are uploaded at an online platform (https://freshwaterwatch. thewaterhub.org/) for open public consultation. In the first three years (2013-2015), more than 600 participants joined the project in Brazil and obtained data on a bimonthly basis in 80 streams and rivers. Results from comparative analyses with other countries participating of the FWW project have been published in peer-reviewed journals (e.g., Loiselle et al. 2016).

The relevance of freshwater issues is of growing importance in Brazil. São Paulo, Rio de Janeiro and Curitiba have had ongoing severe water shortages with increasing eutrophication in major water bodies. Water supply sources have reached the lowest water levels/discharges on record and cyanobacterial blooms are common. Despite the country has a significant percentage of the global water reserves, water pollution, inadequate land use and anthropogenic impacts have been compromising ecosystem services and the access to clean and safe water (e.g., Cunha et al. 2016). The Adopt a River approach appeals to the local participants as a means to contribute to this local priority by supporting scientists and environmental agencies. Identifying appropriate channels to make the data available for policy and decision makers has been a challenge but was a key element to maintaining participation. Although the participants' activities also contribute to the global FWW research objectives, participant's contribution to local priorities was seen as a key incentive to their long-term participation.

In the first 30 months of activity, there were 1,082 datasets uploaded by 307 different users, working in teams. The number of repeat datasets obtained by single participants met the expected logarithmic trend (Figure 8). Interestingly, the data production shows a higher participation with respect to other studies, as $80 \%$ of the data was acquired by nearly $50 \%$ of the participant teams, compared to the more common 80:20 rule found in most projects (Sauermann and Franzoni 2015). The engagement of the Brazilian volunteers was also attributed to the importance of the communication channels and tools that were used to keep them motivated. Communication strategies included online blogs, email communication, continuous learning activities and regular webinars. For the worldwide projects we analyzed, information on communication and engagement was rarely reported (Figure 7f), and we recommend special attention to this issue to achieve longer periods of volunteers' active participation.

While the project showed a high activity rate, clear barriers to long term commitment were present: i) volunteers build their own sample collectors; ii) activities are performed outside of work hours and require travel to sample locations; iii) sample ecosystems are often present in degraded areas (i.e., with effluents discharge, presence of solid waste 
and other unpleasant characteristics). Sampling frequency was every two months and to maintain participation, regular engagement activities (e.g. online interaction, follow-up workshops and events) were conducted.

It was not possible to involve the volunteers in data interpretation/analyses but temporal and spatial analysis tools were provided online. Data gathering is the dominant task in the majority of citizen science projects (see Figure 1g). The effective involvement of citizen scientists in decision-making (including delineation of scenarios and discussion of management options with professional scientists and managers) has been more deeply studied in recent years and participatory models combined to citizen science are already available (e.g., Gray et al. 2017). The direct transfer of the knowledge/ information gained from citizen science into environmental conservation decision making remains unclear and a major challenge in many projects (Newman et al. 2017).

Engagement with Brazilian government agencies regarding information exchange is ongoing. Increasing the spatial and temporal coverage of environmental monitoring is one of the most important challenges faced by local environmental agencies and the data obtained by project participants represents a unique information base. At the moment (2016), citizen science is still not fully embedded within public agencies and barriers remain, largely related to institutions' structure and integration with strategic planning (Blaney et al. 2016).

\section{CONCLUSIONS}

The number and potential impact of citizen science initiatives are increasing worldwide. However,

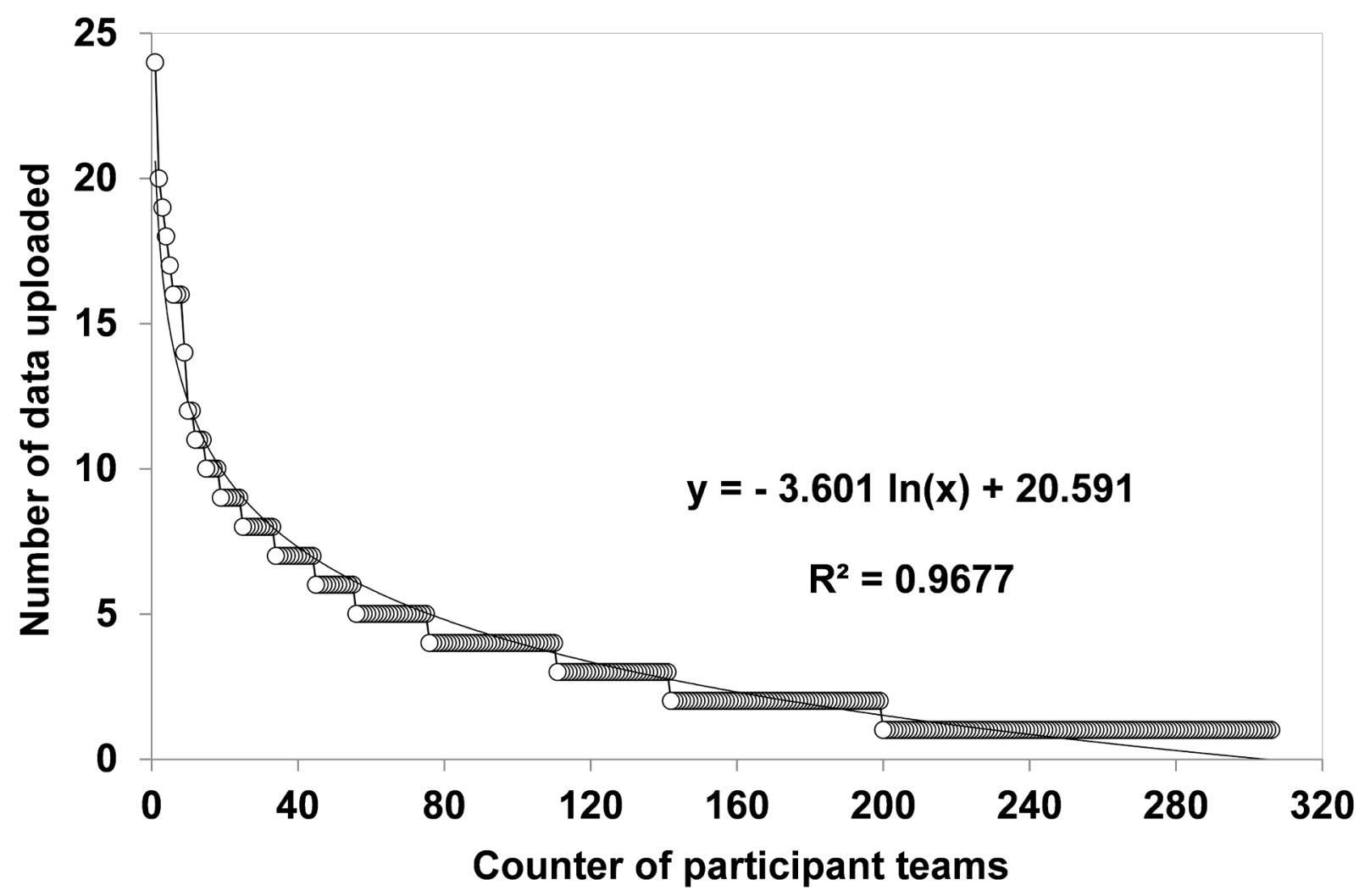

Figure 8 - Datasets acquired by each volunteers of the Adopt a River project up to January 2015 (excluding datasets obtained by the University of São Paulo and Earthwatch Institute). 
there is a strong element of trial and error in many projects, and the comparison of best practices and project structure between different initiatives remains difficult. From the present study, it is possible to identify a successful citizen science program as one with a good match between project proponents and participants, project goals and local priorities, participant profiles and engagement practices, scientific methods and funding. Long term engagement is favored when activities have implications for the local community (i.e. for the participants themselves), while the participation in a larger scale (global) effort provides additional incentives for initial engagement, networking and learning. Quality control, long term participation and personal commitment benefit from an initial investment in training and continuous learning.

In the Adopt a River project, a combination of academic, private and NGO partners aimed at addressing a major local issue through field based training and long term engagement. The methods were appropriate to meet both scientific and monitoring objectives and the extended nature of the funding and commitment allowed for the generation of a robust dataset. The success of the project indicates that the data acquisition methods and engagement approaches adopted were appropriate for the objectives set.

The opportunity and potential benefits for citizen science in Brazil are elevated. It is a megadiverse country with a large and well educated population. There is a clear need for open and accessible data and a greater involvement of non-scientists as citizen scientists to help face the country's multiple environmental challenges. The present analysis shows that citizen science is a growing part of the international scientific community area of practice.

\section{ACKNOWLEDGMENTS}

We thank HSBC Bank for the financial support to the "Adopt a River" project in Brazil, under the scope of the HSBC Water Programme. Our sincere grateful to all HSBC "Citizen Science Leaders" involved with the project. We also thank the environmental engineering undergraduate students from the Universidade de São Paulo who are members of the "Adopt a River" research team.

\section{REFERENCES}

ABOLAFYA M, ONMUS O, ŞEKERCIOĞLU ÇH AND BILGIN R. 2013. Using Citizen Science Data to Model the Distributions of Common Songbirds of Turkey Under Different Global Climatic Change Scenarios. PLOS ONE 8(7): e68037.

ABOUT GOOGLE SCHOLAR. 2015. Available from: https:// scholar.google.com/intl/en/scholar/about.html. Cited: November 2015.

ARVANITIDIS C ET AL. 2011. Engaging the broader community in biodiversity research: the concept of the COMBER pilot project for divers in ViBRANT. ZooKeys 150: 211-229.

AU J, BAGCHI P, CHEN B, MARTINEZ R, DUDLEY SA AND SORGER GJ. 2000. Methodology for public monitoring of total coliforms, Escherichia coli and toxicity in waterways by Canadian high school students. J Environ Manage 58: 213-230.

BÄCKSTRAND K. 2003. Civic science for sustainability: reframing the role of experts, policy-makers and citizens in environmental governance. Global Environ Polit 3: 24-41.

BEASLEY DAE, BENSON EP, WELCH SM, REID LS AND MOUSSEAU TA. 2012. The use of Citizen Scientists to Record and Map 13-Year Periodical Cicadas (Hemiptera: Cicadidae: Magicicada) in South Carolina. Fla Entomol 95: 489-491.

BEEL J AND GIPP B. 2009a. Google Scholar's ranking algorithm: an introductory overview. Pages 230-241. Proceedings of the 12th International Conference on Scientometrics and Informetrics (ISSI'09). Rio de Janeiro (Brazil).

BEEL J AND GIPP B. 2009b. Google Scholar's ranking algorithm: the impact of citation counts (an empirical study). Pages 439-446. Research Challenges in Information Science, 2009. RCIS 2009. Third International Conference on. IEEE.

BIRD TJ ET AL. 2014. Statistical solutions for error and bias in global citizen science datasets. Biol Conserv 173: 144 154. 
BLANEY RJP, PHILIPPE ACV, POCOCK MJO AND JONES GD. 2016. Citizen Science and Environmental Monitoring: Towards a Methodology for Evaluating Opportunities, Costs and Benefits. Final Report on behalf of UK Environmental Observation. Available at http:// www.ukeof.org.uk/resources/citizen-science-resources/ Costbenefitcitizenscience.pdf. Cited: January 2017.

BONNEY R, BALLARD H, JORDAN R, MCCALLIE E, PHILLIPS T, SHIRK J AND WILDERMAN CC. 2009a. Public Participation in Scientific Research: Defining the Field and Assessing Its Potential for Informal Science Education. A CAISE Inquiry Group Report. Online Submission, $58 \mathrm{p}$.

BONNEY R, COOPER CB, DICKINSON J, KELLING S, PHILLIPS T, ROSENBERG KV AND SHIRK J. 2009b. Citizen science: a developing tool for expanding science knowledge and scientific literacy. BioScience 59: 977-984.

BROOK RK, KUTZ SJ, VEITCH AM, POPKO RA, ELKIN BT AND GUTHRIE G. 2009. Fostering community-based wildlife health monitoring and research in the Canadian North. EcoHealth 6: 266-278.

BURGOS A, PÁEZ R, CARMONA E AND RIVAS H. 2013. A systems approach to modeling Community-Based Environmental Monitoring: a case of participatory water quality monitoring in rural Mexico. Environ Monit Assess 185: 10297-10316.

BUSS DF. 2008. Desenvolvimento de um índice biológico para uso de voluntários na avaliação da qualidade da água de rios. Oecologia Brasiliensis 12: 520-530.

CASTILLA EP, CUNHA DGF, LEE FWF, LOISELLE S, HO KC AND HALL C. 2015. Quantification of phytoplankton bloom dynamics by citizen scientists in urban and periurban environments. Environ Monit Assess 187: 1-11.

CATLIN-GROVES CL. 2012. The citizen science landscape: from volunteers to citizen sensors and beyond. International Journal of Zoology 2012: Article ID 349630.

CONRAD C. 2006. Towards Meaningful Community-Based Ecological Monitoring in Nova Scotia: Where are we versus where we would like to be. Environments 34: 2536.

CONRAD C AND DAOUST T. 2008. Community-based monitoring frameworks: Increasing the effectiveness of environmental stewardship. Environ Manage 41: 358-366.

CONRAD CC AND HILCHEY KG. 2011. A review of citizen science and community-based environmental monitoring: issues and opportunities. Environ Monit Assess 176: 273291.

COOPER CB, DICKINSON J, PHILLIPS T AND BONNEY R. 2007. Citizen science as a tool for conservation in residential ecosystems. Ecol Soc 12: Art. 11.

COUVET D, JIGUET F, JULLIARD R, LEVREL H AND TEYSSÈDRE A. 2008. Enhancing citizen contributions to biodiversity science and public policy. Interdiscipl Sci Rev 33: 95-103.

CRALL AW, JORDAN R, HOLFELDER K, NEWMAN GJ, GRAHAM J AND WALLER DM. 2013. The impacts of an invasive species citizen science training program on participant attitudes, behavior, and science literacy. Public Underst Sci 22: 745-764.

CUNHA DGF, DODDS WK AND CALIJURI MC. 2011. Defining nutrient and biochemical oxygen demand baselines for tropical rivers and streams in São Paulo State (Brazil): a comparison between reference and impacted sites. Environ Manage 48: 945-956.

CUNHA DGF, SABOGAL-PAZ LP AND DODDS WK. 2016. Land use influence on raw surface water quality and treatment costs for drinking supply in São Paulo State (Brazil). Ecol Eng 94: 516-524.

DANIELS DP, KROSNICK JA, TICHY MP AND TOMPSON T. 2012. Public opinion on environmental policy in the United States. The Oxford Handbook of US Environmental Policy, p. 461-486.

DANIELSEN F ET AL. 2009. Local participation in natural resource monitoring: a characterization of approaches. Conserv Biol 23: 31-42.

DAUME S, ALBERT M AND VON GADOW K. 2014. Forest monitoring and social media-Complementary data sources for ecosystem surveillance? Forest Ecol Manag 316: 9-20.

DELUCA TH, APLET GH, WILMER B AND BURCHFIELD J. 2010. The unknown trajectory of forest restoration: a call for ecosystem monitoring. J Forest 108: 288-295.

DEVICTOR V, WHITTAKER RJ AND BELTRAME C. 2010. Beyond scarcity: citizen science programmes as useful tools for conservation biogeography. Divers Distrib 16: 354-362.

DIAS R AND FIGUEIRA V. 2010. O turismo de observação de aves: um estudo de caso do município de Ubatuba/SPBrasil. Revista de Estudos Politécnicos 8: 85-96.

DICKINSON JL, SHIRK J, BONTER D, BONNEY R, CRAIN RL, MARTIN J, PHILLIPS T AND PURCELL K. 2012. The current state of citizen science as a tool for ecological research and public engagement. Front Ecol Environ 10: 291-297.

DONNELLY A, CROWE O, REGAN E, BEGLEY S AND CAFFARRA A. 2014. The role of citizen science in monitoring biodiversity in Ireland. Int J Biometeorol 58: 1237-1249.

ELWOOD S. 2010. Geographic information science: Emerging research on the societal implications of the geospatial web. Prog Hum Geog 34: 349-357.

ELY E. 2008. Volunteer monitoring and the democratization of science. The Volunteer Monitor 19: 1-5.

EVANS C, ABRAMS E, REITSMA R, ROUX K, SALMONSEN L AND MARRA PP. 2005. The Neighborhood Nestwatch Program: Participant outcomes 
of a citizen-science ecological research project. Conserv Biol 19: 589-594.

FERREIRA MA, SOARES L AND ANDRADE F. 2012. Educating citizens about their coastal environments: beach profiling in the Coastwatch project. J Coast Conserv 16: 567-574

FERSTER CJ AND COOPS NC. 2013. A review of earth observation using mobile personal communication devices. Comput Geosci 51: 339-349.

GALLOWAY AW, TUDOR MT AND HAEGEN WMV. 2006. The reliability of citizen science: a case study of Oregon white oak stand surveys. Wildlife Soc B 34: 1425-1429.

GIAIA. 2016. Independent Group for Environmental Impact Assessment. First interim report. Available at: http:// en.giaia.eco.br/wp-content/uploads/2016/10/First-InterimReport-GIAIA_revised.pdf. Cited: December 2016.

GRAY S ET AL. 2017. Combining participatory modelling and citizen science to support volunteer conservation action. Biol Conserv 208:76-86.

HAYWOOD BK AND BESLEY JC. 2014. Education, outreach, and inclusive engagement: towards integrated indicators of successful program outcomes in participatory science. Public Underst Sci 23: 92-106.

HOBBS SJ AND WHITE PC. 2012. Motivations and barriers in relation to community participation in biodiversity recording. J Nat Conserv 20: 364-373.

HUNTER J, ALABRI A AND INGEN C. 2013. Assessing the quality and trustworthiness of citizen science data. Concurrency and Computation: Practice and Experience 25: 454-466.

JACSÓ P. 2008. Google scholar revisited. Online Inform Rev 32: 102-114.

KEBO S AND BUNCH MJ. 2013. Canadian ENGOs in governance of water resources: information needs and monitoring practices. Environ Monit Assess 185: 94519460.

KENNEY DS. 1999. Historical and Sociopolitical Context of the Western Watersheds Movement1. J Am Water Resour As 35: 493-503.

KENNEY DS. 2001. Are community-based watershed groups really effective? Confronting the thorny issue of measuring success. Across the great divide: Explorations in collaborative conservation and the American West, p. 188-193.

KIM S, ROBSON C, ZIMMERMAN T, PIERCE J AND HABER EM. 2011. Creek watch: pairing usefulness and usability for successful citizen science. Pages 2125-2134. Proceedings of the SIGCHI Conference on Human Factors in Computing Systems. ACM.

KRASNY ME, RUSS A, TIDBALL KG AND ELMQVIST T. 2014. Civic ecology practices: Participatory approaches to generating and measuring ecosystem services in cities. Ecosyst Serv 7: 177-186.
LEPCZYK CA. 2005. Integrating published data and citizen science to describe bird diversity across a landscape. J Appl Ecol 42: 672-677.

LOISELLE SA, CUNHA DGF, SHUPE S, VALIENTE E, ROCHA L, HEASLEY E, BELMONT PP AND BARUCH A. 2016. Micro and Macroscale Drivers of Nutrient Concentrations in Urban Streams in South, Central and North America. PLOS ONE 11: e0162684.

LOWRY CS AND FIENEN MN. 2013. CrowdHydrology: crowdsourcing hydrologic data and engaging citizen scientists. Ground Water 51: 151-156.

LUCKY A, SAVAGE AM, NICHOLS LM, CASTRACANI C, SHELL L, GRASSO DA, MORI A AND DUNN RR. 2014. Ecologists, educators, and writers collaborate with the public to assess backyard diversity in The School of Ants Project. Ecosphere 5: art78.

MAGURRAN AE, BAILLIE SR, BUCKLAND ST, DICK JM, ELSTON DA, SCOTT EM, SMITH RI, SOMERFIELD PJ AND WATT AD. 2010. Long-term datasets in biodiversity research and monitoring: assessing change in ecological communities through time. Trends Ecol Evol 25: 574-582.

MARTIN-MARTIN A, ORDUNA-MALEA E, HARZING A-W AND LÓPEZ-CÓZAR ED. 2017. Can we use Google Scholar to identify highly-cited documents? J Informetr 11: 152-163.

MCKINLEY DC, BRIGGS RD AND BARTUSKA AM. 2013. Reprint of: When peer-reviewed publications are not enough! Delivering science for natural resource management. Forest Policy Econ 37: 9-19.

MILNE R, ROSOLEN S, WHITELAW G AND BENNETT L. 2006. Multi-party monitoring in Ontario: Challenges and emerging solutions. Environments 34: 11-23.

NEUHAUS C, NEUHAUS E AND ASHER A. 2008. Google Scholar Goes to School: The Presence of Google Scholar on College and University Web Sites. The Journal of Academic Librarianship 34: 39-51.

NEWMAN G ET AL. 2017. Leveraging the power of place in citizen science for effective conservation decision making. Biol Conserv 208: 55-64.

NEWMAN G, GRAHAM J, CRALL A AND LAITURI M. 2011. The art and science of multi-scale citizen science support. Ecol Inform 6: 217-227.

O'FAIRCHEALLAIGH C. 2010. Public participation and environmental impact assessment: Purposes, implications, and lessons for public policy making. Environ Impact Asses 30(1): 19-27.

OVERDEVEST C, ORR CH AND STEPENUCK K. 2004. Volunteer stream monitoring and local participation in natural resource issues. Hum Ecol Rev 11: 177-185.

PRICE SJ AND DORCAS ME. 2011. The Carolina Herp Atlas: an online, citizen-science approach to document amphibian and reptile occurrences. Herpetol Conserv Bio 6: 287-296. 
ROTMAN D, PREECE J, HAMMOCK J, PROCITA K, HANSEN D, PARR C, LEWIS D AND JACOBS D. 2012. Dynamic changes in motivation in collaborative citizenscience projects. Pages 217-226. Proceedings of the ACM 2012 conference on Computer Supported Cooperative Work. ACM.

ROY HE, POCOCK MJO, PRESTON CD, ROY DB, SAVAGE J, TWEDDLE JC AND ROBINSON LD. 2012. Understanding citizen science and environmental monitoring: Final report on behalf of UK environmental observation framework.

SAUERMANN H AND FRANZONI C. 2015. Crowd science user contribution patterns and their implications. P Natl Acad Sci USA 112: 679-684.

ŞEKERCIOĞLU ÇH. 2012. Promoting community-based bird monitoring in the tropics: Conservation, research, environmental education, capacity-building, and local incomes. Biol Conserv 151: 69-73.

SHARPE A AND CONRAD C. 2006. Community based ecological monitoring in Nova Scotia: challenges and opportunities. Environ Monit Assess 113: 395-409.

SHEPPARD SA, WIGGINS A AND TERVEEN L. 2014. Capturing quality: retaining provenance for curated volunteer monitoring data. Pages 1234-1245. Proceedings of the 17th ACM conference on Computer supported cooperative work \& social computing. ACM.

SHIRK JL ET AL. 2012. Public participation in scientific research: a framework for deliberate design. Ecol Soc 17: art. 29.

SHWARTZ A, COSQUER A, JAILLON A, PIRON A, JULLIARD R, RAYMOND R, SIMON LAND PRÉVOTJULLIARD A-C. 2012. Urban biodiversity, city-dwellers and conservation: How does an outdoor activity day affect the human-nature relationship? PLOS ONE 7: e38642.

SILVERTOWN J. 2009. A new dawn for citizen science. Trends Ecol Evol 24: 467-471.
SINCLAIR AJ AND DIDUCK AP. 2001. Public involvement in EA in Canada: a transformative learning perspective. Environ Impact Asses 21: 113-136.

STEWART JM AND SINCLAIR AJ. 2007. Meaningful public participation in environmental assessment: perspectives from Canadian participants, proponents, and government. Journal of Environmental Assessment Policy and Management 9: 161-183.

THORNHILL I, LOISELLE SA, LIND K AND OPHOF D. 2016. The Citizen Science Opportunity for Researchers and Agencies. BioScience 66(9): 720-721.

TOOMEY AH AND DOMROESE MC. 2013. Can citizen science lead to positive conservation attitudes and behaviors? Hum Ecol Rev 20: 50-62.

TREGIDGO DJ, WEST SE AND ASHMORE MR. 2013. Can citizen science produce good science? Testing the OPAL Air Survey methodology, using lichens as indicators of nitrogenous pollution. Environ Pollut 182: 448-451.

WALTERS WH. 2007. Google Scholar coverage of a multidisciplinary field. Inform Process Manag 43: 11211132.

WEI JW, LEE BPY-H AND WEN LB. 2016. Citizen Science and the Urban Ecology of Birds and Butterflies - A Systematic Review. PLOS ONE 11(6): e0156425.

WIGGINS A AND CROWSTON K. 2011. From conservation to crowdsourcing: A typology of citizen science. Pages 1-10. System Sciences (HICSS), 2011. 44th Hawaii international conference on. IEEE.

WRIGHT PA AND STEVENS T. 2012. Designing a longterm ecological change monitoring program for BC Parks: ecological monitoring in British Columbia's parks. BC J Ecosyst Manag 13: 87-100.

YANG K AND MEHO LI. 2007. Citation Analysis: A Comparison of Google Scholar, Scopus, and Web of Science. Proceedings of the American Society for Information Science and Technology 43: 1-15. 